\title{
Analyzing the Relationship between Environmental Planning Policies and Climate Change: Multinomial Logit Regression Model Evaluation of Tarrant County, Texas
}

\author{
Kiranmayi Raparthi \\ School of Urban and Public Affairs, University of Texas at Arlington, Arlington, USA \\ Email: kiranmayi.raparthi@mavs.uta.edu
}

Received 28 December 2014; accepted 15 January 2015; published 22 January 2015

Copyright (C) 2015 by author and Scientific Research Publishing Inc.

This work is licensed under the Creative Commons Attribution International License (CC BY). http://creativecommons.org/licenses/by/4.0/

(c) (i) Dpen Access

\begin{abstract}
Climate change is regarded as one of the greatest challenge human society is facing in this century. The debate on climate change raises the issue of the need to mainstream climate change mitigation in environmental planning. However this has remained research rhetoric and is not transformed to practice. One reason for this gap between research and environmental planning practice might be lack of empirical evidences that analyzes if a relationship between environmental planning policies and climate change mitigation exists. Most planners consent that cities have an ability to mitigate climate change by integrating and implementing environmental policies. However, lack of statistical studies supporting the ability of environmental planning policies in mitigating climate change might have probably halted the process of mainstreaming climate change mitigation in urban planning to some extent. This study evaluated 30 cities comprehensive plans in Tarrant County, Texas for the presence of environmental planning policies that focus on climate change mitigation. Multinomial logistic regression analysis signifies that city's environmental planning policies have an ability to mitigate climate change. Thereby, this research has an implication for mainstreaming environmental planning policies in urban planning accordingly mitigate climate change from a local level perspective.
\end{abstract}

\section{Keywords}

Climate Change Mitigation, Environmental Planning Policies, Regression 


\section{Introduction}

Global climate change is possibly one of the greatest threats human society is facing in the 21st century. According to the National Aeronautics and Space Administration's (NASA), Surface Temperature Analysis Report (2007), since 1850 the warmest years that have been recorded all occurred from 1998, with the year 2005 being noted as the warmest year. Based on improved scientific data and general observations such as increase in atmospheric temperatures, increased rainfalls and rising sea levels, The Intergovernmental Panel on Climate Change (IPCC) affirms that climate change is unequivocal (IPCC, 2007a).

Almost $80 \%$ of the world population lives in urban areas (Kates \& Torrie, 1998). Urban activities consume huge amounts of energy to improve the quality of life and as a result emit about $78 \%$ of carbon-dioxide $\left(\mathrm{CO}_{2}\right)$ gas into the atmosphere (Grimm et al., 2008; Stern \& Taylor, 2007). Hence, urban areas significantly increase $\mathrm{CO}_{2}$ level in the atmosphere thereby, contribute to climate change. According to the Environmental Planning Agency (EPA), major sources of $\mathrm{CO}_{2}$ emissions are electricity accounting for $38 \%$, transportation emitting $31 \%$, industrial activities accounting for $14 \%$ of $\mathrm{CO}_{2}$ emissions followed by residential and commercial activities emitting $10 \%$ and non-fossil fuel combustion accounting to $6 \%$.

Cities not only contribute to climate change by emitting large amounts of $\mathrm{CO}_{2}$, but also experience the resulting impacts of climate change (Bell \& Batterson, 1978). Anticipated impacts of global climate change such as high temperatures, rising sea levels, strong storms, increased risk of droughts and floods, economic losses and heat related illness and diseases are anticipated to affect all aspects of human life. Recent scientific evidence reveals that 160 million people in 20 coastal mega-cities of the world are expected to be directly impacted by rise in sea-level (Nicholls, 1995). Hence, the impacts of climate change are very alarming and addressing climate change mitigation is warranted.

Although, various United Nations (UN) agencies and urban planners have repetitively acknowledged that urban planning and practices can significantly mitigate climate change, lack of empirical evidences that showcase the impact of local level urban planning policies in mitigating climate change, has hampered the implementation of such policies at the local level.

This research puts forth an effort to analyze how theoretical suppositions about the capacity of local urban planning to respond to climate change can be mainstreamed into local planning policies by developing a statistical study that analyzes the ability of local urban planning policies to mitigate climate change.

Specifically the research question that is to be answered is: Does a relationship exist between cities environmental policies and physical characteristics of a city.

\section{Urbanization and Climate Change}

Urbanization is happening rapidly. It is analyzed that by 2007, almost half of the world's population live in urban areas. This productivity is mainly dependent upon the availability of infrastructure services. Infrastructure such as roads, mass transportation, roads, water supply and solid waste management not only increase the productivity of urban areas but also improves the quality of life in these areas.

Economic growth generally implies the need for more land to accommodate urban development (residential uses, industrial and commercial uses) and basically refers to the conversion of agricultural land into urban based industries and services. In developing countries, urbanization and per capita income increase at the same rate as productivity increases. So, rapid productivity and high GDP implies improvements in industries and services, transportation production and information technologies thereby having a profound effect on urbanization (Quigley, 1998, Romer, 1986; Lucas, 2007). Rapid urbanization and improvements in technologies have spurred economic growth (Quigley, 2009). Hence, Urbanization in simple terms means the development of industries which means increased $\mathrm{CO}_{2}$ emissions and thereby contributes to climate change. So, it is important for both the developing and developed countries to address climate change.

Urban areas as concentrations of large economic activities encompass residential, commercial, industrial, and infrastructure services. Thereby has a significant impact on climate change. It is evident that urban areas through sprawl increase the usage of cars thereby contributing to climate change. This means that more the sprawl more is the $\mathrm{CO}_{2}$ emissions. Similarly urban areas means increased residential and commercial buildings. More energy is required to heat and light the buildings (McCarney, 2009). Increased consumption of energy leads to more generation of energy and eventually increased emissions thereby adding more $\mathrm{CO}_{2}$ emissions to the atmosphere. Increased area of a building requires more energy to heat and light. According to the Clinton Foundation, urban 
areas are responsible for about 75 percent of GHG emissions that are released into the atmosphere.

\section{Sustainable Development and Climate Change}

According to the Intergovernmental Panel on Climate Change (IPCC), a strong relationship exists between sustainable development and climate change. On one hand, climate change has an impact on ecosystem, adversely affects the living conditions of human's and also the economic growth thereby, affecting the sustainable development of a community. On the other hand, sustainable development protects the environment from degradation and also reduces GHG emissions that cause climate change by promoting sustainable projects that focus on transportation efficiency, natural preservation and resource conservation. Hence, impacts of climate change affect sustainable development and sustainable development eventually leads to climate change mitigation.

In relation to urban planning, addressing climate change is an integral element of sustainable development policies. By promoting sustainable development, a community can make a major contribution towards climate change mitigation by enhancing a community's climate change mitigation capacity. At the local level, Berke (1995) identifies a set of sustainability principles that are mostly addressed within a community to ensure sustainable development. They are: harmony with nature; livable built environments, place based economy; equity; polluters pay and responsible regionalism. He advocates that sustainable principles that are employed in urban planning do not tend to effectively mitigate climate change (Berke, 1995).

It is generally acknowledged that sustainable development policies are interpreted very broadly and so it is difficult to assess their capability of addressing climate change. For instance, Complete streets is a policy initiative that is implemented at the local level to enhance the livability in a city by building streets that are safer, more livable and welcoming to everyone. This policy makes streets to be user-friendly to the old and young, wheelchair users and walkers, bicyclists and motorists, bus and train riders. However, this initiative does not necessarily imply that a community is committed to reducing vehicle-miles-traveled and, consequently greenhouse gas emissions.

On the other hand, certain policies such as building livable environments that tend to promote mixed use developments; bicycle and pedestrian travel to reduce the need for commuting long distances thereby reduce vehicular emissions and prove beneficial in addressing climate change. This initiative unlike the complete streets directly implies that a community is focused on reducing GHG emissions. Hence, sustainable development policies are certainly complex in nature since they try to address the socio-economic and environmental issues in a broader context.

Likewise, climate change policies that emphasize on promoting energy efficiency polices and renewable energy polices tend to reduce $\mathrm{CO}_{2}$ emissions and also prove to be economically beneficial. However, they may not tend to promote sustainable development as they may or may not create jobs, improve health benefits. For this reason though sustainable development and mitigating climate change are certainly interrelated, yet planning for sustainable development doesn’t mean planning for climate change. Therefore, many international negotiations advocate that it is essential to integrate climate change mitigation policies in urban planning to effectively mitigate climate change.

\section{Relationship between Environmental Planning Policies and Urban Environment}

The Urban environment is widely conceptualized of consisting three components namely human environment, biophysical environment and public policy environment (Godschalk, 1996). The human environment comprises of individuals, community and their related institutions such as social values, cultural values, housing and work. The second component is referred to the bio-physical environment. It consists of the biotic components of the urban landscape that are essential for the development and evolution of the human environment. The third and most essential component of the urban environment is the policy environment. It is the local institutional framework, which consists of regulations, strategies and policies for efficiently managing both the human environment and the bio-physical environment so that a sustainable urban environment can be achieved (Berke, 2006).

In most countries, urban planning refers to the spatial distribution of residential, commercial, industrial and recreational activities over a widespread area and generally involves integration of various components of planning namely land use planning, transportation planning and environmental planning. Through urban planning, local governments have an ability to respond to the changing social, economic and environmental conditions within their cities by controlling the distribution of various land uses and planning decisions related to local de- 
velopment (Agyeman, Evans, \& Kates, 1998). Researchers focusing on the literature of, evaluating urban planning and local planning policies analyzed that, urban planning policies have an ability to promote sustainability and natural resiliency performance (Berke, Godschalk, Kaiser, \& Rodriguez, 2006). Likewise, researchers of climate change acknowledged that, policies that target $\mathrm{CO}_{2}$ reduction can facilitate effective climate change mitigation (Mcevoy et al., 2006). Hence, urban planning policies by incorporating coordination among land use, transportation and environmental planning might have an ability to mitigate climate change.

Local comprehensive plans, master plans and development plans are considered as an important constituent of this local public policy environment as they provide the essential and important guidelines for spatial distribution of various social, cultural and economic and functions within the urban environment. Hence, it can be deduced that the urban form which mainly comprises of different land uses, infrastructure and socio-economic functions, is a result of intimate connections between the human environment, bio-physical environment and policy environments (Berke, 2006).

Literature on evaluating comprehensive plans also confirms that local master plans act as a blueprint for guiding the growth and development of a community (Berke, Godschalk et al., 2006). The existing literature on Indian planning structure and organization confirms that master plans of Indian cities with their regulatory power, have an ability to influence the socio-economic characteristics within the local bio-physical environment and are responsive to the community's growth and development (McCarney, 2009). Hence, it can be concluded that Indian master plans act as an interface between the human environment and the bio physical environment and have an ability to influence the interaction between the socio-economic characteristics and urban ecology.

Research that evaluated community's master plans indicate the ability of policy mandates to influence the socio economic and urban landscape characteristics (human and biophysical environment). Hence it can be deduced that master plans and comprehensive plans encompass the essential characteristics of influencing the quality of life in a community through policy management. Since, the interactions between the human and physical environment affects climate change.

\section{Opportunities for Climate Change Mitigation}

Various global, regional and local impacts of climate change suggest that urban areas act as an interface between the components of climate change and urban activities. Various urban activities results in increased GHG emissions thereby, contributing to an increase in atmospheric temperatures and subsequently impacting the urban areas. Thus, urban areas not only result in causing climate change but are also adversely affected by climate change (Brown, 2001, 2008; Nicholls, 1995). In order to overcome the increasing consequences of climate change there is a need for communities to efficiently reduce their $\mathrm{CO}_{2}$ emissions (mitigation action) and develop climate change resilient cities (adaptation action) (Mcevoy et al., 2006).

In the literature of climate change, mitigation activities are broadly defined as strategies that tend reduce greenhouse gas emissions especially $\mathrm{CO}_{2}$ gas emissions or promote greenhouse sinks (IPCC, 2007b). Climate change mitigation strategies are mainly developed to reduce $\mathrm{CO}_{2}$ emissions into the atmosphere thereby not only safeguard the environment but also the humans who are most likely to be affected by the impacts of climate change (Stehr \& Storch, 2005). $\mathrm{CO}_{2}$ reduction activities mostly include but are not limited to promoting public transportation, improving energy efficiency, infrastructural investments and implementation of renewable energy (Laukkonen et al., 2009). According to McCarney, climate change mitigation strategies mainly tend to target five sectors that are considered to be responsible for emitting large amounts of $\mathrm{CO}_{2}$ gas. They are: transportation, energy supply, industry, buildings, and waste management.

Generally, most researchers consider mitigation of climate change as a global, more or less a regional issue and responsibility. According to them, a major amount of GHG emissions are mainly generated from power generation industries. So, it is necessary for national level policies to target these industries and thereby significantly reduce their GHG emissions (Lashof \& Tirpak, 1990; Lim, Burton, Malone, \& Huq, 2005). However, recently, there is an increasing research that focuses on analyzing the impacts of urban form, urban patterns and urban characteristics on carbon emissions. These studies conclude that by altering the spatial patterns of urban development the $\mathrm{CO}_{2}$ emissions of a community can be significantly reduced (Condon, 2010; Ewing, 2008; Wheeler, 2008; Hough, 2004).

Incorporating changes to the urban form by increasing the density within a community, by altering the design form, promoting regional accessibility and transit availability, and promoting the usage of low carbon energy 
statistically prove to be efficient in reducing $\mathrm{CO}_{2}$ emissions to a considerable extent (Ewing \& Cervero, 2010). For instance, transportation emissions which are primarily a result of car travel and one of the major sources of $\mathrm{CO}_{2}$ gas can be reduced to some extent by reducing car travel through promoting better development patterns or considerable changes to existing patterns (Glaeser, 2008). In addition, Individual behavioral choices to rely on public transport, car pooling and use bicycle mode or walking for short trips will all add up to reducing the transportation emissions which is one of the major contributor to GHG emissions. Hence, mitigation policies are no more limited to international and regional level negotiations (Kyoto protocol), but can also be implemented at local level.

\section{Reducing Climate Change Impact on Cities}

Schlosberg (2008) highlights that most of the climate change mitigation actions currently taking place to reduce $\mathrm{CO}_{2}$ emissions in cities are informed by urban planners. The various mitigation strategies can be broadly categorized into "compact city" approach and the "green city" approach. The "compact city" approach emphasizes on high density development within a city (densification) and the "green city" approach emphasizes the promotion of new developments as a result of the polycentric growth of a city (spatial expansion).

The "compact city" approach emphasizes that high density development can be ascertained by promoting future development of a city within the existing city limits. This requires an effective land use transportation planning approach and also incentives that encourage not only reducing distances between various activities and car travel demand but also reducing single family homes demand as they have a high demand for energy. Alternatively the "green city" approach emphasizes the urban design centered aspect of the developing urban sub-centers by promoting mixed land use developments. This involves the promotion of mass transit routes, and improvements in architectural designs.

\section{Mainstreaming Climate Change Concerns in Local Urban Planning}

Discussion of integrating climate change concerns into mainstream urban planning and being considered as a new aspect of sustainability has just started evolving. Themes of sustainability, smart growth, and new urbanism have been a part of planning concerns and have been mainstreamed into master plans. Likewise, master plans have the ability to also mainstream climate change concerns by including climate change management policies that reduces or moderates the impacts of climate change in the master plans.

Researchers who advocate mainstreaming climate change mitigation into urban planning have identified a set of planning actions that benefit in achieving $\mathrm{CO}_{2}$ reduction. Climate change mitigation effective planning policies focus on promoting low building energy use, reducing vehicle miles, creating dense urban environments and green urban spaces. All these policies eventually reduce $\mathrm{CO}_{2}$ emissions (Kahn, 1996). Cervero (1997) identified the 3 D's namely density, diversity and design as a model for sustainable urbanism. Later, Ewing (2008) in addition to the 3 D's adds two more components thereby puts forth five key components for climate change mitigation and addresses them as the 5 D's. These are: accessibility to destination, short distance between work and transit, increased density; increased diversity in land uses; and small block designs. The main benefit of all these aspects is the significant reduction in vehicle miles travelled and eventually the reduction of $\mathrm{CO}_{2}$ emissions.

In addition to these aspects, Ewing (2008) also suggest urban growth boundaries, workforce housing within close proximity to jobs, pedestrian friendly surroundings and low energy efficient building design standards. Recently, compact urban form is also closely related to climate change mitigation (Ewing, 2008). The justification behind this is that low density development is associated with more sprawl that lead to more vehicles miles travelled and increased $\mathrm{CO}_{2}$ emissions. Recently low density is also related to large single family dethatched units with large interior spaces that lead to more energy consumption and eventually more energy demand. This eventually increases GHG emissions (Ewing, 2008).

The Climate Protection Agreement recommends a set of both short and long-term activities for mitigating climate change (ICLEI, 2005). A set of short-term activities that is relevant to planning are: planting shady street trees; maintaining urban forests, encourage car-pooling and mass-transit; promoting usage of green energy; strict residential and commercial building codes; promoting reuse and recycling programs and public education. Long-term actions include: promote high-density, relocating facilities to reduce travel time; ordinances to limit sprawl, infill development and Brownfield redevelopment; preserve open space; and infill development.

Climate change researchers agree that for policies to effectively mitigate climate change it must constitute a 
mix of climate change mitigation and adaptation actions. Policies and actions that emphasize in limiting or reducing $\mathrm{CO}_{2}$ emissions contribute to the climate change mitigation activities.

\section{Methodology}

Logistic analysis is one of the most widely used statistical analyses to explain the probability of an event to happen or what are the odds that something takes place. For example, if there is $90 \%$ probability that it may rain today then there is a $10 \%$ chance that it may not rain today. Several independent variables can be included in the logistic analysis to determine their relation with the dependent variable thereby strengthen the analysis. Specifically in this research, logistic analysis is used address the following research question:

\subsection{Dependent Variable}

A relationship exists between cities environmental policies and physical characteristics of a city.

\subsection{Independent Variables}

The independent variables that might have an impact on the ability of planning policies to mitigate climate change are-

- Income $\left(X_{1}\right)$

- Sprawl Index $\left(X_{2}\right)$

- Carbon employment $\left(X_{3}\right)$

- Non profit employment $\left(X_{4}\right)$

- Use of public transit $\left(X_{5}\right)$

\subsection{Model}

$$
D V=\alpha+\beta_{1} X_{1}+\beta_{2} X_{2}+\beta_{3} X_{3}+\beta_{4} X_{4}+\beta_{5} X_{5}+\varepsilon
$$

This model can be written as:

Logged odds (Ability to mitigate climate change) $=\alpha+\beta_{1}$ (Income) $+\beta_{2}$ (sprawl index) $+\beta_{3}$ (Carbon employment) $+\beta_{4}$ (non-profit employment) $+\beta_{5}$ (Use of public transit) $+\varepsilon$

\subsection{Hypothesis}

Hypothesis 1: The probability of urban planning policies, to mitigate climate change is less for cities with higher per-capita income.

Hypothesis 2: The probability of urban planning policies to mitigate climate change is less for cities with high sprawl index value.

Hypothesis 3: The probability of urban planning policies to mitigate climate change is more for cities that use public transport as a means to commute to and from work.

Hypothesis 4: The probability of urban planning policies to mitigate climate change is more for cities with high employment in nonprofit sector than cities with high employment in the carbon sector.

\section{Research Framework}

An environmental impact assessment (EIA) is generally referred to as an assessment of the potential impacts a proposed project may have on the environment. Cities which are focused towards having an EIA tend to cause less harm to the environment and have an intention to reduce their reducing their greenhouse gas emissions. Hence, it can be deduced that cities with an EIA component in their comprehensive plans tend to develop planning policies that focus towards $\mathrm{CO}_{2}$ emission reduction thereby have an ability to mitigate climate change. This study considers 30 cities comprehensive plans in Tarrant County, Texas. These cities comprehensive plans are evaluated for the presence of urban planning policies that focus on $\mathrm{CO}_{2}$ emission reduction by analyzing if the comprehensive plans have an environmental impact assessment component.

In logistic regression, the dependent variable is a dichotomous (binary) variable and so it is necessary to assign a value $(0-1)$ to the dependent variable by coding. Cities that have an environmental impact assessment 
component in their comprehensive plans; will also have an ability to mitigate climate change and so are coded as 1 (Yes = 1). If a city does not have an environmental impact assessment and analysis category in their comprehensive plans then the city is coded as $0(\mathrm{No}=0)$. After coding the dependent variable, binominal logit analysis using the above mentioned independent variables is undertaken. All the independent variables are interval variables except for the use public transit variable. A dummy variable is created for the use of public transit. Cities that use public transit are coded as 1 (Use public transit $=1$ ) and cities that do not use public transit are coded as 0 (Don't use public transit $=0$ ).

Of the 30 sample cities, 17 city's comprehensive plans have an environmental impact assessment component in their comprehensive plan. Accordingly, 17 city's were coded as " 1 ” since they had an EIA component and 13 city's that did not have an EIA component were coded as “0”.

\section{Results}

To reject the null hypothesis regression analysis generally performs statistical tests to compute probability referred as a $p$ value. Hence, small $p$-values reflect small probabilities and suggest that the variable/coefficient that has small $p$ values is important in the model. As such $p$ values that range between .01 and .10 are considered to be significant; with $p<.01$ to be highly significant; $p<.05$ moderately significant and $p<.10$ to be marginally significant. Hence, small p values reflect small probability of error and importance of the coefficients. Accordingly from Table 1 it is observed that all the independent variables that are included in the study are statistically significant. Sprawl is considered to highly significant since it significance $(p)$ value is <.01 (Sig = .009). Income is considered to be moderately significant since it significance $(p)$ value is $<.05$ (Sig $=.013$ ). The other independent variables public transport, employment in the carbon sector, non-profit sector employment are considered to be marginally significant since their significance $(p)$ value is $<.10$ (Sig $=.094$, Sig $=.075$, Sig $=.099$ respectively).

The regression coefficients (B; Exp (B)) help in identifying the nature of the relationship with the Dependent variable and also its impact/strength on the dependent variable. It is observed that income has a negative relationship towards the dependent variable $(\mathrm{B}=-.063$; Exp $(\mathrm{B})=-.939)$ and sprawl, public transport, employment in the carbon sector, non-profit sector employment have a positive relationship towards the dependent variable ( $\mathrm{B}=.775 ; \mathrm{B}=3.087 ; \mathrm{B}=.021 ; \mathrm{B}=.013$ respectively).

On the whole, the results show that there is a significant relationship between the dependent variable and independent variables. The Nagelkerke R square to some extent describes how much of the variance in the dependent variable is explained by the independent variables. Table 2 describes the "Goodness of Fit" (model summary) which depicts that the Nagelkerke R square is .633. This means that a city's income, sprawl, nature of employment and travel behavior account for an estimated $63 \%$ of the variation in its urban planning policies ability to mitigate climate change (63\% of the variance in the outcome is being affected by the independent variables).

In sum, it is observed that sprawl, income, are considered to be highly and moderately significant respectively, and followed by use of public transport, non-profit sector employment and employment in the carbon sector which are marginally significant. All the independent variables have a positive relationship towards the dependent variable except for income which has a negative relation towards the dependent variable. $63 \%$ of the variance in the outcome is being affected by the independent variables.

\section{Analysis}

From Table 1 it is observed that, the income of a city is considered to be significant (Sig. $=.013)$ and has a negative relationship towards the ability of urban planning policies to mitigate climate change $(\mathrm{B}=-.063)$. Negative relationship implies that wealthier the cities; less likely will their urban planning policies ability to mitigate climate change. From the odds ratio for income $(\operatorname{Exp}(B)=-.939)$ it can be deduced that high income cities are $6 \%$ less likely to environmental related policies in their master plans (or) high income cities are .93 times less likely to have environmental related policies in their master plans.

Thereby, supporting our first hypothesis which states that, the probability of urban planning policies, to mitigate climate change is less for wealthier cities. One reason behind this hypothesis is that wealthier communities prefer to use own transportation to commute to and from work thereby increase the need for parking spaces within a city. As a result, their urban planning policies lack an ability to mitigate climate change. 
Table 1. Logistic regression estimation of urban planning policies ability to mitigate climate change.

\begin{tabular}{ccccccc}
\hline & B & S.E & Wald & Df & Sig. & Exp(B) \\
\hline Income & -.063 & .025 & 6.226 & 1 & .013 & -.939 \\
Sprawl Index & .775 & .295 & 6.881 & 1 & .009 & 2.170 \\
Empl_Carbon & .021 & .012 & 3.162 & 1 & .75 & 1.021 \\
Empl_NonProfit & .013 & .008 & 2.729 & 1 & .099 & 1.013 \\
Public Transit & 3.087 & 1.841 & 2.813 & 1 & .094 & 21.910 \\
Constant & -15.073 & 8.370 & 3.242 & 1 & .072 & .000 \\
\hline
\end{tabular}

Table 2. Goodness of Fit.

\begin{tabular}{ccc}
\hline & Model Summary & \\
\hline-2 Log likelihood & Cox \& Snell R Square & Nagelkerke R Square \\
\hline $21.880^{\mathrm{a}}$ & .472 & .633 \\
\hline
\end{tabular}

${ }^{\mathrm{a} E s t i m a t i o n ~ t e r m i n a t e d ~ a t ~ i t e r a t i o n ~ n u m b e r ~} 7$ because parameter estimates changed by less than .001 .

The sprawl index of a city is also highly significant $($ Sig. $=.009)$ and has a positive relationship towards the city's urban planning policies ability to mitigate climate change $(B=.775)$. This means that for every unit increase in sprawl, the model estimates the logged odds for urban planning policies ability to mitigate climate change increases by nearly a unit. In other words, more the sprawling nature of a city more is the urban planning policies ability to mitigate climate change. According to the analysis, the odds ratio for sprawl is (Exp (B) = 2.170) meaning that that cities with high sprawl index are $117 \%$ more likely to have environmental related policies while controlling all the other variables in the model (or) sprawling cities are 2.17 times more likely to have environmental related policies.

This is in contrary to our second hypothesis which states that, the probability of urban planning policies to mitigate climate change is less for cities with high sprawl index value. Thereby, emphasizing that, it is increasingly difficult for urban planners to control sprawl development of a city and so they compensate for the negative impacts of sprawl on climate change by promoting urban planning policies that focus more on green open spaces and use of public transport.

The use of public transit variable is also considered to be significant (Sig. $=.094)$. It is to be reminded that this variable is a binary variable coded (1) if the city uses public transit and coded (0) if the city does not use public transit. According to our analysis, cities that use public transport increases the logit of the estimated logged odds for urban planning policies to mitigate climate change by 3 units $(B=3.087)$. The odds ratio is $(\operatorname{Exp}(B)=21.910)$ meaning that cities that use public transport are $2091 \%$ likely to have environmental related policies in their master plans while controlling all the other variables in the model (Or) cities that use public transit are 3.087 times more likely to have environmental related policies in their master plans. Our hypotheses that the probability of urban planning policies to mitigate climate change is more for cities that use public transport as a means to commute to and from work is true. This strengthens our earlier analysis on wealthier communities wherein using own transportation reduces the ability of the city's urban planning policies to mitigate climate change.

As per our last hypothesis which states that urban planning policies of nonprofit sector will have an ability to mitigate climate change when compared to urban planning policies cities with high employment in the carbon sector. However, our analysis is in contrary to this hypothesis. It is analyzed that both carbon employment and nonprofit employment have a positive relationship towards planning polices ability to mitigate climate change. It is analyzed that the odds ratio for carbon employment and nonprofit employment is 1.02 and 1.01 respectively. This means that cities that have higher percentage of employment in carbon emission industries are $2 \%$ likely to have environmental related policies in their master plans while controlling all the other variables in the model (Or) cities that have higher number of employment in carbon emission industries are 1.02 times more likely to have environmental related policies in their master plans when compared to that of a city with less employment in carbon emissions.

Cities that have higher percentage of employment in Non Government organizations are 1\% likely to have environmental related policies in their master plans while controlling all the other variables in the model (Or) ci- 
ties that have higher number of employment in NGO are 1.01 times more likely to have environmental related policies in their master plans when compared to that of a city with less employment in NGOs.

On the whole, it can be analyzed that sprawling cities and cities that use public transit are more likely to have urban planning policies that have an ability to mitigate climate change and wealthier cities are less likely to have urban planning polices with an ability to mitigate climate change.

The model for this analysis can be written as follows:

Logged odds (Ability of urban planning policies to mitigate climate change) $=(-15.073)-.063$ (Income) +.775 (Sprawl) +.021 (Carbon employment) +.013 (Non-profit employment) +3.08 (Use of public transit) $+\varepsilon$

For a city with income of $\$ 52,000$, Sprawl index of 52, carbon employment of 140,000 and NGO employment of 24,000 and no public transport is:

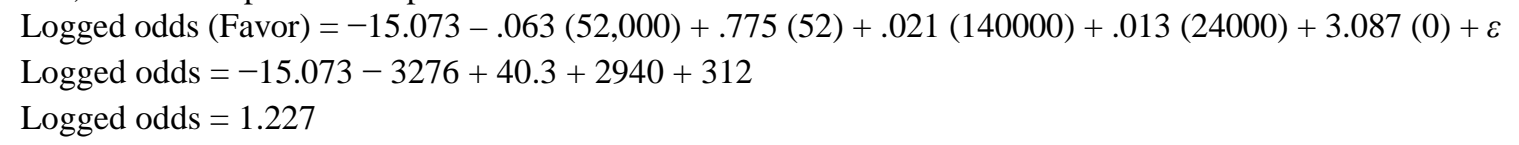

Probability for a city to have environmental related policies $=\frac{\mathrm{e}^{\text {Log Odds }}}{1+\mathrm{e}^{\mathrm{Log} \text { Odds }}}$

Probability $=\frac{\mathrm{e}^{1.227}}{1+\mathrm{e}^{1.227}}=\frac{3.4}{1+3.4} 0.77 \times 100=77 \%$

The probability for such a city to have environmental related policies in their master plans is $77 \%$. (OR) Such a city is 77 times more likely to have environmental related policies in their master plans. As such, a relationship exists between policies and physical characteristics of a city.

\section{Conclusions}

The research outcomes provide interesting insights on the ability of urban planning policies to mitigate climate change. It is observed that planning polices of a city do have the ability to mitigate climate change. Specifically The study discovered significant relationship between urban planning polices of sprawling cities and cities that use public transport have an ability to mitigate climate change. This research highlights that urban planning polices of wealthier cities have ales ability to mitigate climate change thereby emphasizes the need for wealthier cities to develop urban planning policies that focus on climate change mitigation.

The study has implication for mainstreaming of climate change mitigation policies in urban planning policies. The convergence of urban planning policies for pursuing the twofold objectives of climate change mitigation and sustainable growth will not only help in achieving an efficient utilization of resources but also facilitates a sustainable development. As climate change is an integral element of sustainable development, this study, recommends urban planners to integrate climate change policies in their comprehensive plans, to achieve the dual effects of both climate change mitigation and sustainable development.

In sum, this study has put forth an effort to fill in the gap between academic research and professional practice within in the context of climate change mitigation, by developing empirical evidences that analyzes whether a statistically significant relationship exists between urban planning policies and climate change mitigation. However, due to the relatively small sample size the statistical power of this analysis may be low yet it still confirms that a relationship does exist and hence there is a scope for strengthening the results by involving a larger sample.

\section{References}

Agyeman, J., Evans, B., \& Kates, R. (1998). Greenhouse Gases Special: Thinking Locally in Science, Practice and Policy. Local Environment, 3, 245-246. http://dx.doi.org/10.1080/13549839808725563

Bell, B. D. G. K., \& Batterson, C. (1978). Service Utilization and Adjustment Patterns of Elderly Tornado Victims in an American Disaster. Mass Emergencies, 3, 71-81.

Berke, P. R., Godschalk, D. R., Kaiser, E. J., \& Rodriguez, D. (2006). Urban Land Use Planning (5th ed). Champaign, IL: University of Illinois Press.

Cervero, R., \& Kockelman, K. (1997). Travel Demand and the 3DS: Density, Diversity, and Design. Transportation Research Part D: Transport and Environment, 2, 199-219. http://dx.doi.org/10.1016/S1361-9209(97)00009-6

Condon, P. M. (2010) Seven Rules for Sustainable Communities. Washington DC: Island Press. 
Ewing, R., \& R. Cervero (2010). Travel and the Built Environment: A Synthesis. Transportation Research Record, 1780

Ewing, R., Bartholomew, K., Winkelman, S., Walters, J., \& Che, D. (2008). Growing Cooler: Evidence on Urban Development and Climate Change. Washington DC: ULI.

Glaeser, E., \& Kahn, M. (2008). The Greenness of Cities: Carbon Dioxide Emissions and Urban Development. UC Los Angeles: California Center for Population Research. http://www.escholarship.org/uc/item/2pk7j5cp

Godschalk, D. R., \& Mills, W. E. (1996). A Collaborative Approach to Planning through Urban Activities. Journal of the American Planning Association, 32, 86-95.

Grimm, N. B., Faeth, S. H., Golubiewski, N. E., Redman, C. L., Wu, J., Bai, X. Y., \& Briggs, J. M. (2008). Global Change and the Ecology of Cities. Science, 319, 756-760. http://dx.doi.org/10.1126/science.1150195

Hough, M. (2004). Cities and Natural Process: The Basis for Sustainability (2nd ed.). London: Routledge.

ICLEI (2005). International Council for Local Environmental Initiatives. http://www.iclei.org/

IPCC (2007a). Climate Change 2007: Summary for Policymakers of the Synthesis Report of the IPCC Fourth Assessment Report. New York: Cambridge University Press.

IPCC (2007b). Climate Change 2007: The Physical Science Basis. In S. Solomon, D. Qin, M. Manning, Z. Chen, M. Marquis, K. B. Averyt, M. Tignor, \& H. L. Miller (Eds.), Working Group I Contribution to the Fourth Assessment Report of the Intergovernmental Panel on Climate Change (p. 996). New York: Cambridge University Press.

Kahn, M. (1996). New Evidence on Trends in Vehicle Emissions. Rand Journal of Economics, 27, 183-196. http://dx.doi.org/10.2307/2555798

Kates, R. W., \& Torrie, R. D. (1998). Global Change in Local Places. Environment, 40, 39-41. http://dx.doi.org/10.1080/00139159809605088

Lashof, D. A., \& Tirpak, D. A. (1990). Policy Options for Stabilizing Global Climate. New York: Hemisphere Publishing.

Laukkonen, J., Blanco, P. K., Lenhart, J., Keiner, M., Cavric, B., \& Kinuthia-Njenga, C. (2009). Combining Climate Change Adaptation and Mitigation Measures at the Local Level. Habitat International, 33, 287-292. http://dx.doi.org/10.1016/j.habitatint.2008.10.003

Lim, B., Spanger-Siegfried, E., Burton, I., Malone, E., \& Huq, S. (2005). Adaptation Policy Frameworks for Climate Change: Developing Strategies, Policies and Measures. Cambridge: Cambridge University Press.

Lucas Jr., R. E., (2007). Trade and the Diffusion of the Industrial Revolution. Frank D. Graham Memorial Lecture, Princeton, NJ: Princeton University.

McCarney, P. (2009). City Indicators on Climate Change: Implications for Policy Leverage and Governance. Paper Prepared for the World Bank's 5th Urban Research Symposium on Cities and Climate Change: Responding to an Urgent Agenda, Marseille, 28-30 June 2009.

Mcevoy, D., Lindley, S., \& Handley, J. (2006). Adaptation and Mitigation in Urban Areas: Synergies and Conflicts. Proceedings of the Institution of Civil Engineers-Municipal Engineer, 159, 185-191. http://dx.doi.org/10.1680/muen.2006.159.4.185

Nicholls, R. J. (1995). Coastal Megacities and Climate Change. Geo Journal, 37, 369-379. http://dx.doi.org/10.1007/BF00814018

Quigley, J. M. (2009). Urbanization, Agglomeration and Economic Development. In M. Spence, P. C. Annez, \& R. M. Buckley (Eds.), Urbanization and Growth, Commission on Growth and Development. Washington DC: The World Bank.

Romer, P. (1986). Increasing Returns and Long-Run Growth. Journal of Political Economy, 94, 1002-1037. http://dx.doi.org/10.1086/261420

Schlosberg, D., \& Rinfret, S. (2008). Ecological Modernization, American Style. Environmental Politics, 17, $254-275$. http://dx.doi.org/10.1080/09644010801936206

Stern, N., \& Taylor, C. (2007). Climate Change: Risk, Ethics, and the Stern Review. Science, 317, 203-204. http://dx.doi.org/10.1126/science.1142920

Wheeler, S. M. (2008). State and Municipal Climate Change Plans: The First Generation. Journal of the American Planning Association, 74, 481-496. http://dx.doi.org/10.1080/01944360802377973 
Scientific Research Publishing (SCIRP) is one of the largest Open Access journal publishers. It is currently publishing more than 200 open access, online, peer-reviewed journals covering a wide range of academic disciplines. SCIRP serves the worldwide academic communities and contributes to the progress and application of science with its publication.

Other selected journals from SCIRP are listed as below. Submit your manuscript to us via either submit@scirp.org or Online Submission Portal.
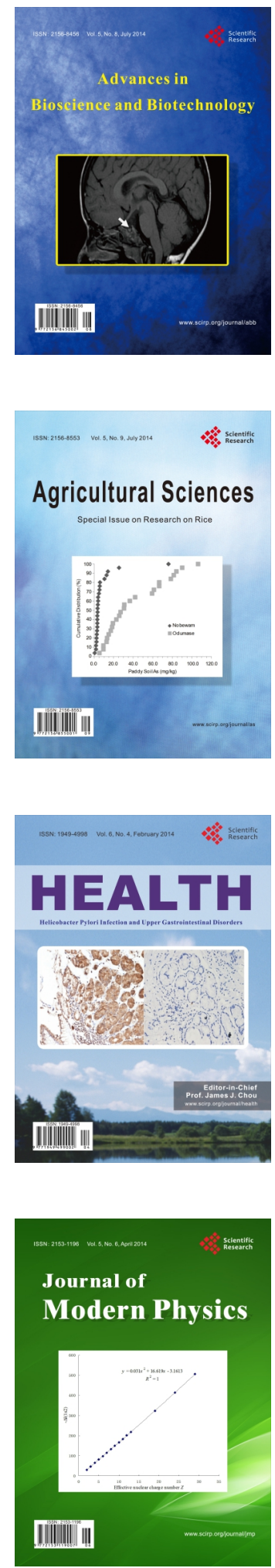
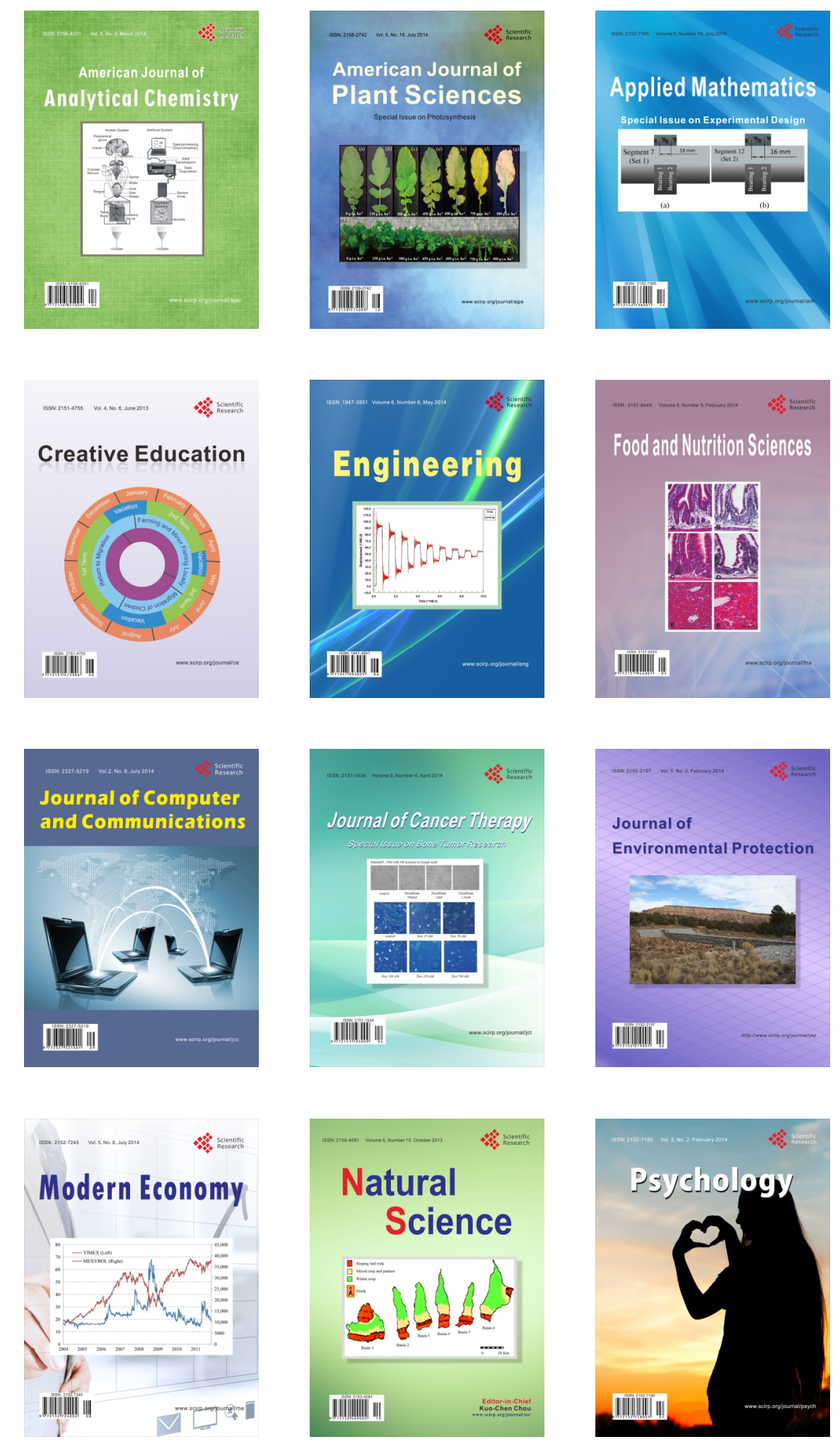